\title{
Big gulps require high drag for fin whale lunge feeding
}

\author{
Jeremy A. Goldbogen ${ }^{1, *}$, Nicholas D. Pyenson², Robert E. Shadwick1 \\ ${ }^{1}$ Department of Zoology, University of British Columbia, 6270 University Boulevard, Vancouver, \\ British Columbia V6T 1Z4, Canada
}

${ }^{2}$ Department of Integrative Biology and Museum of Paleontology, University of California, Berkeley, California 94720, USA

\begin{abstract}
Fin whales Balaenoptera physalus exhibit one of the most extreme feeding methods among aquatic vertebrates. Fin whales, and other rorquals (Balaenopteridae), lunge with their mouth fully agape, thereby generating dynamic pressure to stretch their mouth around a large volume of prey-laden water, which is then filtered by racks of baleen. Despite their large body size, fin whales appear to be limited to short dive durations, likely because of the energetic cost associated with large accelerations of the body during several lunges at depth. Here, we incorporate kinematic data from high-resolution digital tags and morphological data of the engulfment apparatus in a simple mechanical model to estimate the drag acting on a lunge-feeding fin whale. This model also allowed us to quantify the amount of water and prey obtained in a single lunge. Our analysis suggests that the reconfiguration and expansion of the buccal cavity enables an adult fin whale to engulf approximately 60 to $82 \mathrm{~m}^{3}$ of water, a volume greater than its entire body. This large engulfment capacity, however, comes at a high cost because the drag, work against drag, and drag coefficient dramatically increase over the course of a lunge. As a result, kinetic energy is rapidly dissipated from the body, and each subsequent lunge requires acceleration from rest. Despite this high cost, living balaenopterids are not only among the largest animals on earth, but are relatively speciose and exhibit diverse prey preferences. Given this ecological diversity, we frame our results in an evolutionary context, and address the implications of our results for the origin of lunge feeding.
\end{abstract}

KEY WORDS: Lunge feeding $\cdot$ Fin whale $\cdot$ Balaenoptera physalus $\cdot$ Drag $\cdot$ Foraging $\cdot$ Locomotion

Resale or republication not permitted without written consent of the publisher

\section{INTRODUCTION}

Baleen whales (or Mysticeti) are highly streamlined marine mammals that have evolved an efficient locomotor strategy (Williams 1999), which permits highspeed swimming as well as long-distance migration. Mysticetes also rank among the largest vertebrates of all time, and they differ from their sister taxon, the toothed whales (or Odontoceti), by the presence of keratinized baleen plates that hang from the rostrum and serve to filter prey from a volume of ingested water. This feeding strategy occurs in several different modes among living mysticetes (Werth 2000): (1) benthic suction feeding, observed only in the gray whale Eschrichtius robustus; (2) skim or continuous ram feed- ing, which bowhead and right whales (Balaenidae) use exclusively; and, lastly, (3) lunge feeding, the principal mode for rorquals (Balaenopteridae). Some mysticetes have very specialized cranial and mandibular morphologies that restrict them to one mode of feeding (e.g. a highly arched rostrum in balaenids), whereas other mysticetes, like gray whales, can employ different modes as needed (Nerini 1984). Overall, filter feeding in mysticetes allows these predators to process bulk quantities of prey items at a scale commensurate with their comparatively large body size (Sanderson \& Wassersug 1993, Werth 2000).

Lunge feeding, which is formally characterized as intermittent ram suspension feeding (Sanderson \& Wassersug 1993), is a specific behavior documented 
among rorquals that allows individuals to engulf large quantities of water and prey using a series of coordinated events: (1) accelerating the body, (2) lowering the mandibles and presenting the floor of the mouth to oncoming flow, (3) generating dynamic pressure that expands the buccal cavity, (4) closing the mouth around a large volume of water, and (5) expelling this volume through baleen plates located on the roof of the mouth, thereby retaining prey inside the buccal cavity.

The ingestion of water is facilitated by several key morphological features of the rorqual feeding apparatus, including a highly extensible ventral groove blubber (VGB) located on the ventral surface of the throat wall that extends from the snout to the umbilicus (Orton \& Brodie 1987) and massive, unfused mandibles that make up nearly $25 \%$ of the length of the body (Pivorunas 1977, Lambertsen et al. 1995). These bones have been observed to rotate during lunge feeding in several species of rorquals (Lambertsen et al. 1995, Arnold et al. 2005), and this phenomenon serves to increase the area of the mouth exposed to flow (Lambertsen et al. 1995) as well as to maneuver the mandibles around the laterally curved baleen plates (Pivorunas 1976, 1977). Lambertsen et al. (1995) defined 3 different degrees of freedom with respect to jaw movement: (1) alpha - about the long axis of the mandible, (2) delta-jaw abduction, and (3) omega-lateral divergence that occurs at the temporomandibular joint. Ultimately, the magnitude of the engulfed volume is limited morphologically, not only by the size and shape of the mandibles (Lambertsen et al. 1995), but also the capacitance of the mouth provided by the elastic VGB (Orton \& Brodie 1987). The dimensions and mechanical properties of the VGB suggest that the expansion of the buccal cavity is driven solely by the hydrodynamic pressure from swimming (Orton \& Brodie 1987).

The widespread convergence of a streamlined body profile in many flying and swimming organisms reflects the functional and evolutionary importance of minimizing drag during locomotion (Vogel 1994). Such shape dependence on drag reduction has major implications for any organism that must deviate from this ideal form in order to perform life functions. As adept swimmers, rorquals possess highly streamlined bodies powered by flukes with a high aspect ratio, and these morphological specializations are predicted to enable efficient and high-performance locomotion at high speeds (Bose \& Lien 1989). When rorquals lunge feed, however, the process and result of engulfment forces a severe departure from the streamlined paradigm, where the body takes on a distended and bloated shape. It has been hypothesized that lunge feeding entails a high energetic cost, probably due to the drag created by an open mouth at high speeds (Croll et al. 2001, Acevedo-Gutierrez et al. 2002). Recent tagging efforts that have elucidated the detailed kinematics of the body during lunges in fin whales (Goldbogen et al. 2006) demonstrated that fin whales routinely execute several lunges per dive at depths $>200 \mathrm{~m}$. Most notably, each lunge was characterized by a rapid deceleration of the body despite continued swimming (Goldbogen et al. 2006). Together, these lines of evidence suggest a high cost associated with lunge feeding in rorquals due principally to high drag.

Among diving birds and mammals, diving capacity is predicted to increase for larger organisms because of the differential scaling between blood oxygen stores and metabolic rate (Butler \& Jones 1982). Although this scaling relationship does hold across many diverse and independent lineages, it is severely affected by ecological, behavioral and physiological factors (Halsey et al. 2006). For example, blue whales Balaenoptera musculus and fin whales are the largest diving animals, but they do not exhibit the deepest or the longest dive durations (Croll et al. 2001). Instead, the maximum dive durations for blue and fin whales are only 15 to 17 min, less than half the time predicted for their comparatively large body sizes (Croll et al. 2001). Similar maximum dive durations have been observed even for consecutive dives to $>400 \mathrm{~m}$ (Panigada et al. 1999). The energetic cost of lunge feeding has been suggested to be a likely constraint that severely limits foraging time and increases post-dive recovery time at the sea surface (Acevedo-Gutierrez et al. 2002). In contrast, the continuous skim feeding in right and bowhead whales (Balaenidae), the sister group to rorquals and just as massive, does not appear to be constrained by high feeding costs. Balaenid foraging dives are twice as long as most rorquals', even at equivalent depths, and their dives are followed by shorter recovery times at the surface (Krutzikowsky \& Mate 2000). This dichotomy can be attributed to the energetic demands of different feeding strategies between balaenids (continuous ram feeders) and balaenopterids (intermittent lunge feeders) (Croll et al. 2001, Acevedo-Gutierrez et al. 2002).

Although the current data on rorqual foraging are consistent with the hypothesis that lunge feeding is energetically expensive, the actual cost has not been addressed quantitatively. Furthermore, the details regarding the benefit of lunge feeding, such as engulfment capacity, are largely unknown. To test the hypothesis that lunge feeding requires drag, we developed a mechanical model of engulfment for a lunge-feeding rorqual based on mechanical principles and hydrodynamic theory. Additionally, we incorporated kinematic data recorded from high-resolution digital tags and morphological data of the engulfment apparatus into 
the model to quantify engulfment volume and net drag for a lunge-feeding fin whale. We then discuss the implications of our results in the context of fin whale foraging ecology and evolution.

\section{MATERIALS AND METHODS}

Mechanics of the body during lunge feeding. Tag deployments on fin whales Balaenoptera physalus revealed the average speed of the body (for 50 lunges, 7 adults) at $1 \mathrm{~s}$ intervals (Goldbogen et al. 2006); speed of the body was determined by flow noise detected by the hydrophone within the tag and also independently checked for accuracy by kinematic analysis. Average speed and a range corresponding to 2 standard deviations about the mean were incorporated into the model that follows (Fig. 1). In this way, the model accounts for $68 \%$ of the variation in lunge speed observed by tagged fin whales. The derivative of speed with respect to time provided the acceleration profile needed for the hydrodynamic analyses in the present study.

The average body length $L$ is approximately $20 \mathrm{~m}$ for an adult fin whale (Lockyer 1976). This body length was used in order to select other morphological parameters (Table 1) that correspond to the fin whales that were tagged.

Engulfment volume. The volume of water engulfed within a given time increment $V_{i}$ is equal to the product of instantaneous projected mouth area $S_{\mathrm{M}}$ and the distance traveled during that time increment $\Delta x / \Delta t$ :

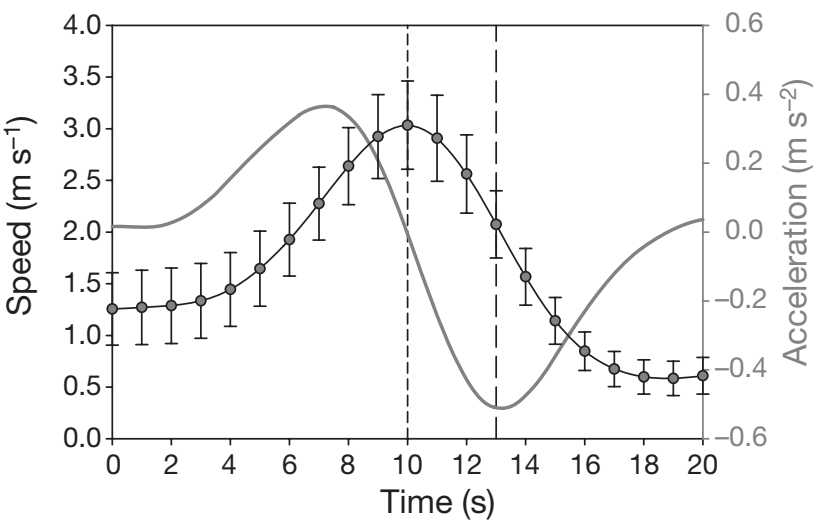

Fig. 1. Balaenoptera physalus. Kinematics of the body during a lunge. Average speed of the body (black line) calculated for 50 lunges performed by 7 fin whales (see Goldbogen et al. 2006). Error bars represent 2 standard deviations about the mean. Acceleration of the body (gray line) is calculated from the change in speed over each $1 \mathrm{~s}$ interval. The vertical, closely dashed line represents the moment when the mouth opens at maximum speed, and the vertical, widely dashed line marks the moment of greatest deceleration, which should occur at maximum gape

$$
V_{i}=S_{\mathrm{M}} \Delta x / \Delta t
$$

The cumulative engulfed volume $V_{\mathrm{E}}$ is the sum of $V_{i}$. Displacement of the body during the lunge was calculated by integrating the area under the velocity profile. This model assumes that the VGB expands rapidly enough so that no spill-over takes place during engulfment.

Table 1. Parameters incorporated into the model. All morphological and physiological parameters correspond to an adult fin whale where the body length $(L)=20 \mathrm{~m}$. Plus or minus symbols represent one standard deviation

\begin{tabular}{|c|c|c|c|}
\hline Parameter & Symbol & Value & Reference \\
\hline Average adult body length & $L$ & $20 \mathrm{~m}$ & Lockyer (1976) \\
\hline Average adult body mass & $M$ & $50000 \mathrm{~kg}$ & Lockyer (1976) \\
\hline Length of ventral grooves & $L_{\mathrm{V}}$ & $8 \mathrm{~m}(0.4 L)$ & Orton \& Brodie (1987 \\
\hline Radius of the body & $R$ & $1.5 \mathrm{~m}$ & Lockyer \& Waters (1986) \\
\hline Body speed & $U$ & see Fig. 1 & Goldbogen et al. (2006) \\
\hline $\begin{array}{l}\text { Projected mouth area as a } \\
\text { function of gape angle }\end{array}$ & $S_{\mathrm{M}}$ & see Fig. 3 & Lambertsen et al. (1995) \\
\hline Baleen filter area & $A_{\mathrm{B}}$ & $3.0 \mathrm{~m}^{2}$ & Kawamura (1980) \\
\hline Baleen fringe diameter & $L_{\mathrm{F}}$ & $\begin{array}{c}\text { Range }=2.5 \times 10^{-2} \text { to } 1.4 \times 10^{-1} \mathrm{~cm} \\
\text { Average }=7.5 \times 10^{-2} \mathrm{~cm}\end{array}$ & Kawamura (1980) \\
\hline Baleen plate spacing & $L_{\mathrm{P}}$ & Average $=0.6 \pm 0.2 \mathrm{~cm}$ & $\begin{array}{l}\text { USNM 504258, 504243; } \\
\text { MVZ 124428; UCMP } 85366\end{array}$ \\
\hline Prey density (krill) & $P_{\mathrm{D}}$ & Average $=0.15 \mathrm{~kg} \mathrm{~m}^{-3}$ & Croll et al. (2005) \\
\hline Daily energetic demand (krill) & $\Gamma$ & $901 \pm 258 \mathrm{~kg} \mathrm{~d}^{-1}$ & Croll et al. (2006) \\
\hline $\begin{array}{l}\text { Average foraging dive duration } \\
\text { and surface recovery time }\end{array}$ & $\left(T_{\mathrm{D}}+T_{\mathrm{S}}\right)$ & $9 \min$ & $\begin{array}{l}\text { Croll et al. (2001); Acevedo- } \\
\text { Gutierrez et al. (2002); } \\
\text { Goldbogen et al. (2006) }\end{array}$ \\
\hline Duration between consecutive lunges at depth & $T_{\mathrm{L}}$ & Average $=30 \mathrm{~s}$ & Goldbogen et al. (2006) \\
\hline Number of lunges per dive & $N_{\mathrm{o}}$ & Average $=4$ & Goldbogen et al. (2006) \\
\hline
\end{tabular}


The average duration between consecutive lunges $T_{\mathrm{L}}$ effectively represents the time required to filter the engulfed volume (Goldbogen et al. 2006). Although the actual filter time could be faster, the whale probably executes another lunge as soon as the previously engulfed volume has been filtered given that dive time is limited. Thus, volumetric flow rate or filter rate $F$ is then defined as:

$$
F=V_{\mathrm{E}} / T_{\mathrm{L}}
$$

If $F$ is distributed over the baleen filter area $A_{\mathrm{B}}$ for a $20 \mathrm{~m}$ fin whale (Kawamura 1980; Table 1), we can define an average flow speed of the engulfed water being filtered by the baleen as:

$$
\check{O}=F / A_{\mathrm{B}}
$$

Furthermore, we can describe the character of flow past the baleen and its fringes as described by the nondimensional Reynolds number $R e$, which is the ratio of inertial to viscous forces:

$$
\mathrm{Re}=\left(\check{O} L_{\mathrm{X}}\right) / v
$$

where $L_{\mathrm{X}}$ is either the distance between consecutive baleen plates $L_{\mathrm{P}}$ or the diameter of the individual fringes $L_{\mathrm{F}}$ and $v$ is the kinematic viscosity of seawater. We highlight this distinction because, in rorquals, water first flows past the fringes located on the lingual side of the baleen, and then the water passes through the baleen plates themselves (Werth 2001). Kawamura (1980) reported measurements for the diameter of baleen fringes for fin whales (Table 1). We measured the distance between consecutive baleen plates on the following museum specimens at the National Museum of Natural History in Washington, DC (USNM 504258, 504243), and the Museum of Vertebrate Zoology (MVZ 124428) and the Museum of Paleontology (UCMP 85366), both at the University of California, Berkeley. We only measured baleen plates that were still intact as a series within the gum. Each specimen was photographed with a scale bar and measured digitally using ImageJ (freeware available at: http://rsb.info. nih.gov/ij/).

Foraging ecology. By combining the engulfment volume generated by the model and previously published data for fin whales and their prey (Table 1), we can predict several parameters that are relevant to fin whale foraging ecology. We can calculate the amount of krill acquired per lunge $K_{\mathrm{L}}$ for a given prey density $P_{\mathrm{D}}$ :

$$
K_{\mathrm{L}}=P_{\mathrm{D}} V_{\mathrm{E}}
$$

Next, we can predict the number of lunges per day $N_{\mathrm{L}}$ required to meet a daily energetic demand $\Gamma$ :

$$
N_{\mathrm{L}}=\Gamma / K_{\mathrm{L}}
$$

and the number of foraging dives per day $N_{\mathrm{F}}$ for a given number of lunges per dive $N_{\mathrm{o}}$ :

$$
N_{\mathrm{F}}=N_{\mathrm{L}} / N_{\mathrm{o}}
$$

We used previous estimates of daily energetic demand calculated by Brodie (1975) and Croll et al. (2006). The foraging time $T_{\mathrm{F}}$ needed to perform $N_{\mathrm{F}}$ for a continuously foraging fin whale:

$$
T_{\mathrm{F}}=\left(T_{\mathrm{D}}+T_{\mathrm{S}}\right) N_{\mathrm{F}}
$$

is related to the time required to perform a foraging dive $T_{\mathrm{D}}$ in addition to the surface time following each dive $T_{\mathrm{S}}$.

Projected mouth area and estimation of gape angle. Projected mouth area $S_{\mathrm{M}}$ as a function of gape angle was previously reported for a $20 \mathrm{~m}$ adult fin whale specimen (Lambertsen et al. 1995). To evaluate any major variation in mouth area among individuals of the same size, we calculated maximum mouth area for 2 other fin whales (USNM 550467, $L=19.7 \mathrm{~m}$; and True's (1904: p 133) Specimen No. 6, Wister Institute, Philadelphia, $L=20.7$ ) following the simple geometric calculation of Lambertsen et al. (1995). We made standardized measurements of the skull and mandibles to determine the functional area of the mouth involved in lunge feeding (Lambertsen et al. 1995). Each calculation was within $1.0 \mathrm{~m}^{2}$ of the maximum mouth area reported by Lambertsen et al. (1995), which is only $12 \%$ of this maximum reported value.

To determine how gape angle changes as a function of time $t$ during a lunge, we first measured the angle between the tip of the rostrum and the tip of the mandibles for a rorqual lunge feeding on schooling fish (BBC Video Blue Planet, Open Seas). This video footage is arguably the best for any rorqual lunge and serves as a vital source of information regarding the change in gape angle over time. The narrator in the footage identifies the individual rorqual as a sei whale Balaenoptera borealis, although Arnold et al. (2005), with whom we agree, identified this individual as a Bryde's whale Balaenoptera brydei. While this individual is not as large as a fin whale, we analyzed this data in order to determine how gape angle changes for a lunge in any rorqual, and then scaled the relative changes in gape angle to be appropriate for a fin whale as suggested by kinematic data from deployed tags. Despite differences in size between Bryde's and fin whales, skull and mandible morphologies are very similar (J. A. Goldbogen, N. D. Pyenson unpubl. data) and we expect similar motions during lunge feeding as would be predicted by dynamic similarity.

Gape angle $\theta$ was analyzed for 2 lunges in which the body was largely perpendicular to the camera (Fig. 2a). 

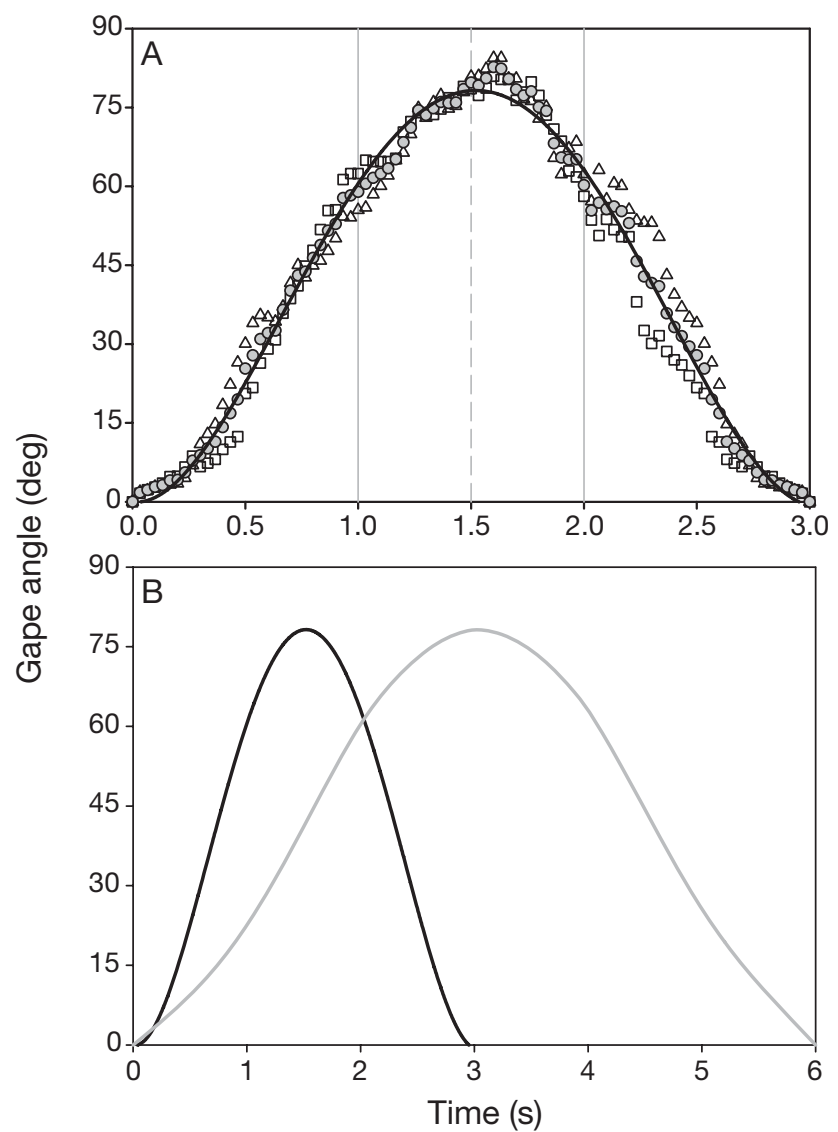

Fig. 2. The amount of time required to lower and raise the mandibles during a lunge is approximately equal. (a) Gape angle $(\theta)$ measured as a function of time $(t)$ during 2 lunges performed by a Bryde's whale Balaenoptera brydei (see 'Materials and methods' for details). $(\square, \Delta)$ Data points for each lunge. Average gape angle $(O)$ is fit by the polynomial regression $(\theta=$ $\left.15.353 t^{4}-93.506 t^{3}+144.07 t^{2}-5.4003 t ; \mathrm{r}^{2}=0.994\right)$. The vertical dashed line indicates maximum gape, whereas the vertical solid lines mark the moments at which the ventral groove blubber starts and stops expanding. (b) These data for a Bryde's whale (black line) were scaled with respect to time, in order to estimate the gape angle during a fin whale lunge (gray line) of longer duration, as indicated by kinematics of the body (Fig. 1)

Each lunge was approximately $3 \mathrm{~s}$ in duration, from mouth opening to mouth closure, with maximum $\theta$ occurring half-way through the lunge at $t=1.5 \mathrm{~s}$. A quadratic spline fit to the average $\theta$ data for each lunge revealed a bell-shaped curve. We recorded the approximate time that the VGB started to expand and when it nearly reached full extension. We then scaled the gape angle profile of a Bryde's whale (average $L=$ $14 \mathrm{~m}, \Delta t=3 \mathrm{~s}$ ) to that of a fin whale (average $L=20 \mathrm{~m}$, $\Delta t=6 \mathrm{~s}$ ) to account for a longer lunge time (Fig. 2b). This scaling agrees with the mechanical principles of engulfment, whereby the mouth opens at maximum velocity and the moment of maximum deceleration occurs at maximum gape (Fig. 1; Goldbogen et al. 2006).

It is important to note that gape angle may also be a function of elevation of the rostrum (Arnold et al. 2005), but this is not expected to affect the model significantly. The area of the rostrum covers a large proportion of the area defined by the mandibles; thus, any elevation of the rostrum will deflect oncoming flow into the mouth.

Hydrodynamic and mechanical modeling. We chose a quasi-steady hydrodynamic analysis to determine the net drag acting on a lunge-feeding fin whale. The mass $M$ of a $20 \mathrm{~m}$ adult fin whale (Table 1) will decelerate $a$ as a function of the net $\operatorname{drag} D$ :

$$
D=M a
$$

Although there certainly is thrust generated by swimming during the lunge, the total drag becomes much greater than the thrust, which is why the body decelerates rapidly despite continued swimming (Goldbogen et al. 2006). Therefore, we will not include thrust in the present model. We obtain a by calculating the change in speed over time from previously published measurements (Goldbogen et al. 2006).

The mass of the system does not include the mass of the engulfed volume. Explicitly leaving the engulfed mass out of the calculation for drag is similar to leaving out the mass of the fluid external to the body that is accelerated, as has been done elsewhere in the unsteady aerodynamics of accelerating (Potvin et al. 2003) or decelerating (Iversen \& Balent 1951) bluff bodies. Thus, the engulfed water is being accelerated (and therefore creates dynamic pressure and drag), but it is not fully accelerated to become part of the system initially. The engulfed volume is enveloped in place because the stretching of the VGB is rapid enough so that the only wake that is produced is by the rigid mandibles and exposed rostrum. The compliance of the ventral pouch also provides some delay so that the whale can close its mouth before water is accelerated up to the speed of the whale, thus preventing a bow wave that would push potential prey away (Brodie 2001).

A force exerted over a distance $\Delta x$ represents work. Swimming against drag represents the work against drag $W$ and is calculated as a product of $D$ and $\Delta x$ :

$$
W=D \Delta x
$$

We can determine the quasi-steady drag coefficient $C_{\mathrm{D}}$, or the drag per unit area divided by the dynamic pressure, at any given instant during the lunge:

$$
C_{\mathrm{D}}=2 M a / \rho S_{\mathrm{T}} U^{2}
$$


where $\rho$ is the density of seawater, $U$ is the instantaneous speed, and $S_{\mathrm{T}}$ is the total projected area of the body. Only $S_{\mathrm{T}}$ is considered in this model, rather than wetted surface area, because at such high $\operatorname{Re}(\mathrm{Re}>$ $\left.10^{7}\right),>97 \%$ of the total drag consists of pressure drag (Vogel 1994).

Projected area of the body is dynamic due to the opening and closing of the jaws and the expansion of the buccal cavity, which together augment the projected area of the ventral side of the body. Total projected area of the body is therefore determined by the sum of ventral $S_{\mathrm{V}}$ and dorsal $S_{\mathrm{D}}$ components of the body represented by half-cylinders:

$$
S_{\mathrm{T}}=S_{\mathrm{V}}+S_{\mathrm{D}}
$$

The dorsal component remains constant throughout the lunge and is calculated as a half-cylinder with a radius $R$, which is determined from previously published measurements of an adult fin whale (Table 1). In contrast, $S_{\mathrm{V}}$ will be determined by $S_{\mathrm{M}}$ before maximum gape, and by the projected area of the expanded buccal cavity $S_{\mathrm{BC}}$ after maximum gape. We can calculate the instantaneous radius $r$ of the buccal cavity given a fixed length of the mouth or ventral grooves $L_{\mathrm{V}}$ (Table 1; Orton \& Brodie 1987) and the cumulative volume $V_{\mathrm{E}}$ from Eq. (1):

$$
r=\sqrt{ }\left(2 V_{\mathrm{E}} / \pi L_{\mathrm{V}}\right)
$$

Thus, before maximum gape:

$$
S_{\mathrm{V}}=S_{\mathrm{M}}
$$

while after maximum gape:

$$
S_{\mathrm{V}}=S_{\mathrm{BC}}=1 / 2 \pi r^{2}
$$

\section{RESULTS}

\section{Kinematics}

The kinematics of the body during a lunge provided a context for which to examine how gape angle $(\theta)$ and projected mouth area $\left(S_{\mathrm{M}}\right)$ vary as a function of time (Fig. 3). Over a time of $6 \mathrm{~s}$, the speed of the body decreased from 3.0 to $0.5 \mathrm{~m} \mathrm{~s}^{-1}$. The mandibles were lowered to a maximum gape $\theta_{\max }$ of approximately $80^{\circ}$ and raised in the same amount of time $(\sim 3 \mathrm{~s})$. Similar compliance of the temperomandibular joint was observed in a wide variety of post mortem experiments in which $\theta_{\max }$ of fin, sei, and minke whales ranged from 85 to $90^{\circ}$ (Lambertsen et al. 1995, Brodie 2001). From skull morphology and an accurate estimate of swimming speed, Brodie (1993) predicted $\theta_{\max }$ to occur in about $3 \mathrm{~s}$, which agrees with the model presented here.
Mandible length for an adult fin whale Balaenoptera physalus was measured as $4.6 \mathrm{~m}$, which traced a path of approximately $14 \mathrm{~m}$ by the tip during engulfment. Thus, the depression and elevation of the mandible tip occur at a mean velocity of $2.4 \mathrm{~m} \mathrm{~s}^{-1}$ for the lunge duration presented here. These results are consistent with those of Kot (2005), who calculated an average elevation of the mandible as $2.8 \mathrm{~m} \mathrm{~s}^{-1}$ for fin whales lungefeeding at the sea surface.

Changes in $\theta$ were tightly associated with changes in $S_{\mathrm{M}}$, with both reaching maxima half-way through the lunge. The sum of the product of forward body displacement and $S_{\mathrm{M}}$ over the course of the lunge resulted in an average engulfment volume of $71 \mathrm{~m}^{3}$ (range: 60 to $82 \mathrm{~m}^{3}$ ). The radius of the half-cylinder representing the buccal cavity increased by $60 \%$ (range: 50 to $70 \%$ ) by the end of the lunge.

\section{Drag}

Gape angle dramatically increased the projected area of the body and therefore strongly affected drag on the body (Fig. 4). Maximum drag (average $=20 \mathrm{kN}$; range: 17 to $22 \mathrm{kN}$ ) occurred at maximum gape. Maximum drag $(t=13.5)$ was approximately 4 times the initial drag $(t=10.5)$. The work against drag correlated with the filling rate of the buccal cavity (Fig. 5). Maxima for work against drag (average $=44 \mathrm{~kJ}$; range: 28 to $58 \mathrm{~kJ}$ ) and filling rate of the buccal cavity (average = $20 \mathrm{~m}^{3} \mathrm{~s}^{-1}$; range: 18 to $23 \mathrm{~m}^{3} \mathrm{~s}^{-1}$ ) occurred when the VGB started to expand. The maximum work against drag $(t=12.5)$ was 3 times greater than initial values $(t=10.5)$.

The drag coefficient ( $C_{\mathrm{D}}$ i referenced to frontal area) increased over the course of a lunge and was positively correlated with the amount of water engulfed (Fig. 4). As the mouth began to open, the average $C_{\mathrm{D}}$ was calculated as $0.21\left(C_{\mathrm{D}}\right.$ range: 0.18 to 0.26$)$. Just before the mouth to closed, $C_{\mathrm{D}}$ had increased by at least an order of magnitude (average $=3.21$; range: 2.20 to 5.13 ).

\section{Filter performance and foraging ecology}

The engulfed volume was filtered at an average rate of $2.4 \mathrm{~m}^{3} \mathrm{~s}^{-1}$ (range: 2.0 to $2.7 \mathrm{~m}^{3} \mathrm{~s}^{-1}$; Table 2). This mass flow distributed over the baleen filter area results in an average flow speed of $0.8 \mathrm{~m} \mathrm{~s}^{-1}$ (range: 0.7 to $0.9 \mathrm{~m} \mathrm{~s}^{-1}$ ). Consequently, the average Reynolds number $(\mathrm{Re})$ for flow past the baleen fringes was 570 (range: 480 to 650). After flowing around the fringes located on the lingual side of the baleen, water must next pass through the baleen plates themselves. The average spacing between fin whale baleen plates 


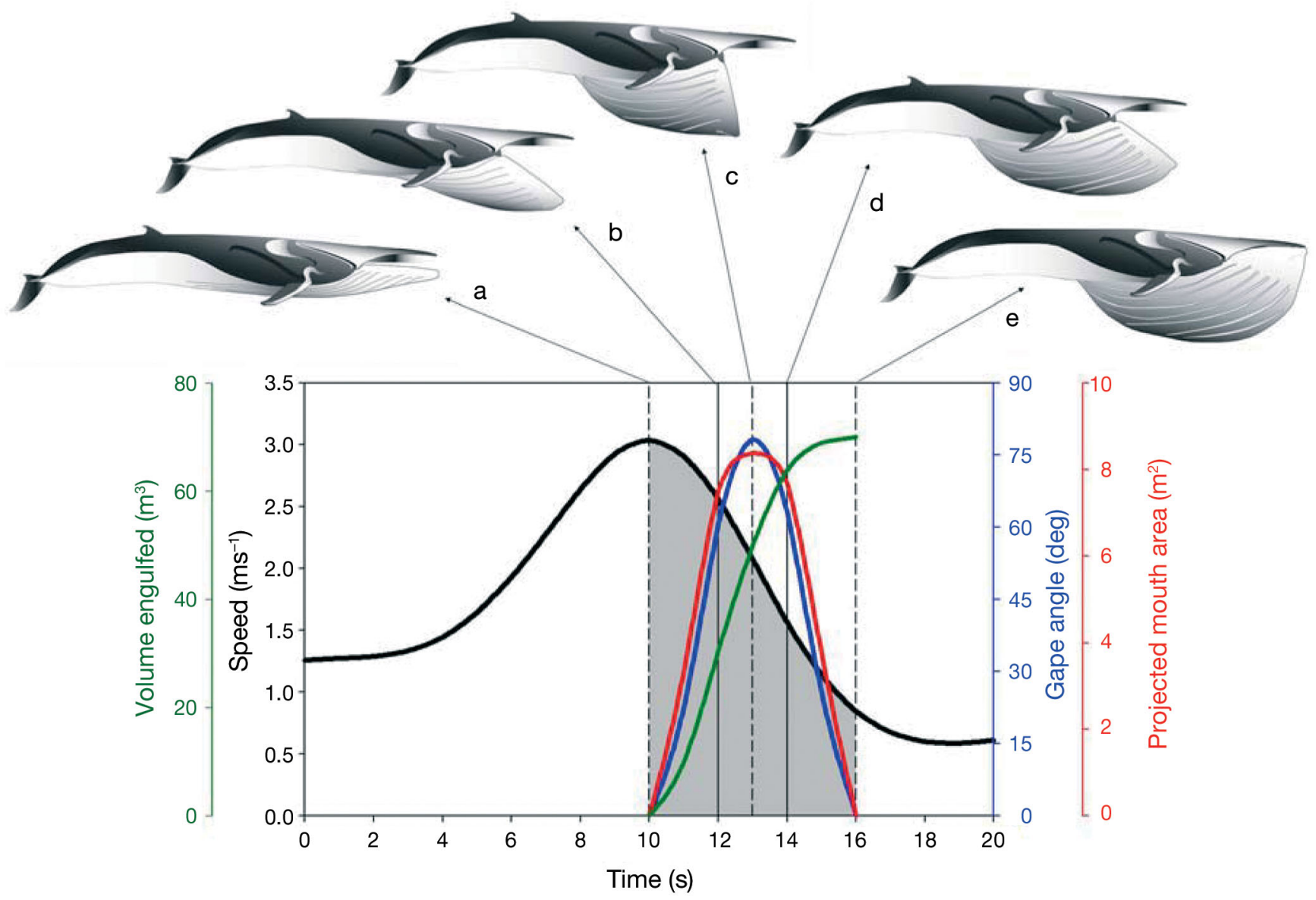

Fig. 3. Balaenoptera physalus. Relationship between gape angle (red line), projected mouth area (blue line), speed (black line) and volume engulfed (green line) in the context of the mechanics of the body during a lunge. Vertical lines mark significant events throughout the lunge cycle represented by each schematic: (a) mouth begins to open, (b) ventral groove blubber (VGB) begins to expand, (c) maximum gape angle, (d) VGB is nearly fully expanded, and (e) mouth closes. The shaded area represents the distance traveled during the lunge. Fin whale vector-based artwork adapted and modified from Folkens (2003)

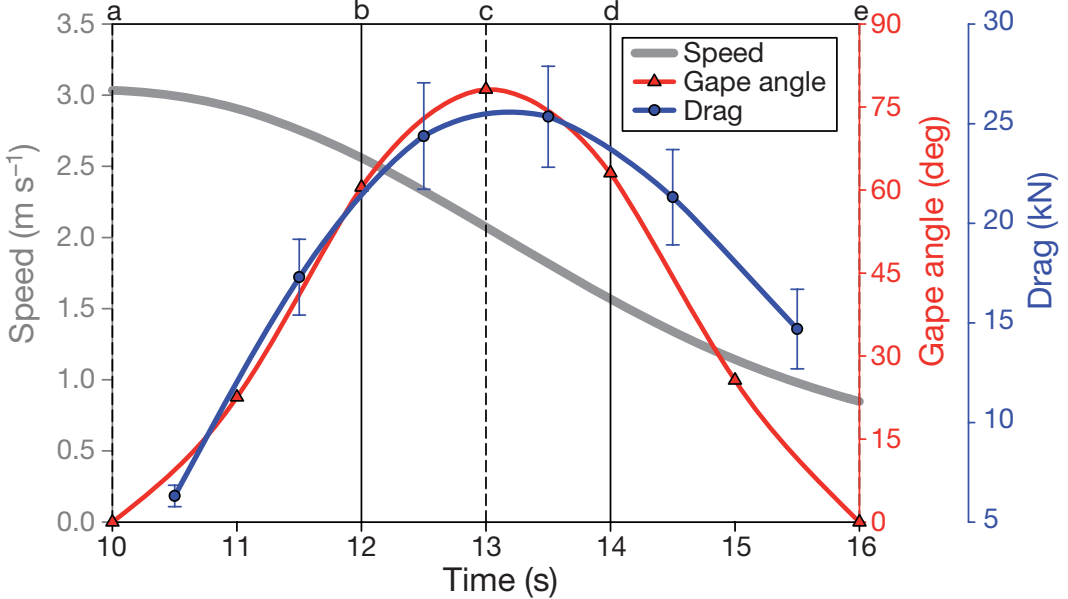

Fig. 4. Balaenoptera physalus. Drag correlates with gape angle. Gape angle dramatically increases projected area of the body (Fig. 1) and therefore becomes the main predictor of drag on the body. a-e: see Fig. 3. Error bars represent 2 standard deviations about the mean yields an Re number well within the recognized inertial hydrodynamic regime (average $=4500$; range: 3800 to 5200).

For an average prey density measured at foraging sites, a fin whale can acquire an average of $11 \mathrm{~kg}$ of krill per lunge (range: 9 to $12 \mathrm{~kg}$ ) for the engulfment capacity calculated in the present study. A fin whale would therefore have to execute an average of 83 lunges $\mathrm{d}^{-1}$ (range: 73 to 100 lunges $\mathrm{d}^{-1}$ ) to fulfill its daily energetic demands. This energetic demand can be met by an average of 21 dives (range: 18 to 25 dives) over an average foraging time of $3.1 \mathrm{~h}$ (range: 2.8 to $3.8 \mathrm{~h}$ ). 


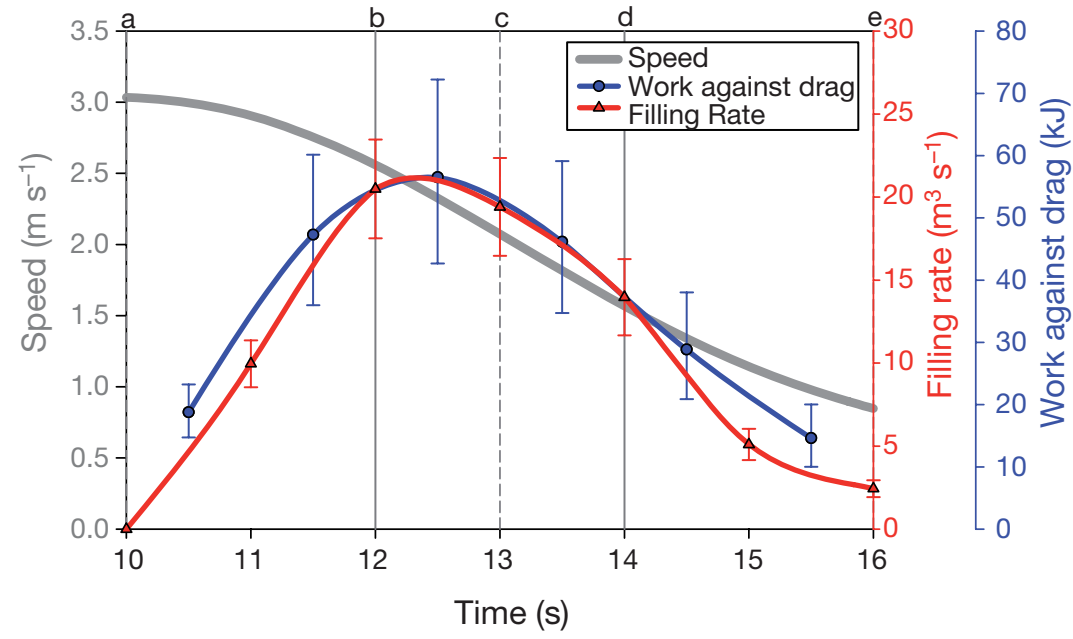

Fig. 5. Balaenoptera physalus. The work against drag correlates with the filling rate of the buccal cavity. Swimming against drag generates the work required to stretch the buccal cavity around the volume of prey-laden water. Here, the reconfiguration of the buccal cavity is represented as a filling rate. Maxima for filling rate and work against drag occur at the time when the buccal cavity begins to expand ( $b$; for $a, c, d, e$, see Fig. 3). Error bars represent 2 standard deviations about the mean

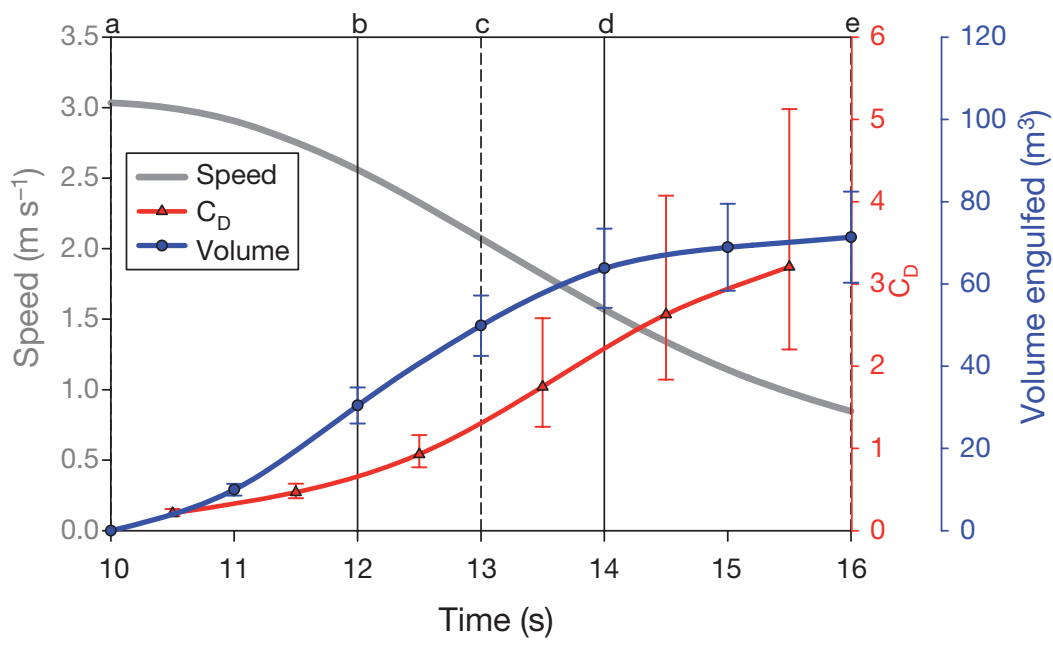

Fig. 6. Balaenoptera physalus. Reconfiguration of the buccal cavity is correlated with an increase in drag coefficient $C_{\mathrm{D}}$. Shape changes associated with the reconfiguration of the buccal cavity (represented here as the cumulative volume engulfed), strongly affects $C_{\mathrm{D}}$ or the amount of dynamic pressure that is converted into drag. a-e: see Fig. 3. Error bars represent 2 standard deviations about the mean

\section{DISCUSSION}

This study demonstrates the extraordinary engulfment capacity and associated mechanical consequences of fin whale Balaenoptera physalus lunge feeding. We present the first testable model of this feeding pro- cess that combines kinematic data recorded from high-resolution digital tags with morphological data of the skull, mandibles, and soft tissues of the body. Our analysis shows an increase in drag related to the expansion and reconfiguration of the buccal cavity during a lunge (Figs. 4 to 6 ). The high drag required to expand the mouth also dissipates the kinetic energy of the body, bringing the body practically to a halt. As a result, each lunge requires acceleration from rest and therefore comes at a high energetic cost. This mechanical consequence is especially important considering that fin whales execute up to 7 lunges dive ${ }^{-1}$ (Goldbogen et al. 2006). The energetic demand of lunge feeding has been implicated in the rapid exhaustion of oxygen stores at depth, resulting in very short dive durations (Croll et al. 2001). Indeed, blue and fin whales that performed more lunges at depth also spent a greater amount of time at the sea surface following those lunges, presumably to replace oxygen stores (Acevedo-Gutierrez et al. 2002). Our results support the hypothesis of AcevedoGutierrez et al. (2002), who first suggested that the energetic cost of lunge feeding is due primarily to drag.

Our results, along with those of Acevedo-Gutierrez et al. (2002), disagree with those of Blix \& Folkow (1995), who concluded that minke whales Balaenoptera acutorostrata do not show any difference in energy expenditure between lunge feeding and cruising. These conclusions were based on respiratory rates, steady swim speed estimates that were apparently not calibrated, and subjective analysis of dive profiles. Blix \& Folkow (1995) failed to account for changes in speed that occur during a lunge under short time scales; these rapid accelerations are a better indicator of lunge feeding than subjective analysis of dive profiles (see Goldbogen et al. 2006). From the limited data available on their diving behavior (Stockin et al. 2001), it appears that minke whales also exhibit short massspecific dive durations much like their larger relatives. Although it seems that lunge feeding is accompanied by an energetic cost for all rorquals, the relative mag- 
Table 2. Parameters generated by the mechanical and hydrodynamic model. The range represents the model output for two standard deviations about the mean body speed calculated for 50 lunges among 7 individual fin whales

\begin{tabular}{|c|c|c|c|}
\hline Parameter & Symbol & Average value & Range \\
\hline Engulfment volume & $V_{\mathrm{E}}$ & $71 \mathrm{~m}^{3}$ & $60-82 \mathrm{~m}^{3}$ \\
\hline Filter rate & $F$ & $2.4 \mathrm{~m}^{3} \mathrm{~s}^{-1}$ & $2.0-2.7 \mathrm{~m}^{3} \mathrm{~s}^{-1}$ \\
\hline Drag (initial) & $D_{\mathrm{i}}$ & $6 \mathrm{kN}$ & $6-7 \mathrm{kN}$ \\
\hline Drag (maximum) & $D_{\max }$ & $20 \mathrm{kN}$ & $17-22 \mathrm{kN}$ \\
\hline Work against drag (initial) & $W_{\mathrm{i}}$ & $19 \mathrm{~kJ}$ & $15-23 \mathrm{~kJ}$ \\
\hline Work against drag (maximum) & $W_{\max }$ & $44 \mathrm{~kJ}$ & $28-58 \mathrm{~kJ}$ \\
\hline Drag coefficient (initial) & $C_{\mathrm{Di}}$ & 0.2 & $0.2-0.3$ \\
\hline Drag coefficient (maximum) & $C_{\text {Dmax }}$ & 3.2 & $2.2-5.1$ \\
\hline $\begin{array}{l}\text { Reynolds number for flow past } \\
\text { Baleen fringes }\end{array}$ & $R e_{\mathrm{F}}$ & 570 & $480-650$ \\
\hline $\begin{array}{l}\text { Reynolds number for flow past } \\
\text { Baleen plates }\end{array}$ & $R e_{\mathrm{P}}$ & 4500 & $3800-5200$ \\
\hline Filtering flow speed & $\check{O}$ & $0.8 \mathrm{~m} \mathrm{~s}^{-1}$ & $0.7-0.9 \mathrm{~m}^{3} \mathrm{~s}^{-1}$ \\
\hline Mass krill obtained per lunge & $K_{\mathrm{L}}$ & $11 \mathrm{~kg}$ & $9-12 \mathrm{~kg}$ \\
\hline $\begin{array}{l}\text { Number of lunges day }{ }^{-1} \text { to match } \\
\text { daily energetic demand }(\Gamma)\end{array}$ & $N_{\mathrm{L}}$ & 83 & $73-100$ \\
\hline $\begin{array}{l}\text { Number of foraging dives } \\
\text { required to execute } N_{\mathrm{L}}\end{array}$ & $N_{\mathrm{F}}$ & 21 & $18-25$ \\
\hline $\begin{array}{l}\text { Foraging time required } \\
\text { to execute } N_{\mathrm{F}}\end{array}$ & $T_{\mathrm{F}}$ & $3.1 \mathrm{~h}$ & $2.8-3.8 \mathrm{~h}$ \\
\hline
\end{tabular}

Wassersug 1993, Lambertsen et al. 1995). Considering the mechanics of these types of elastic structures (Ahlborn 2004), the time it takes to open and close the jaws must be approximately equal. Our results for gape angle dynamics show that it takes the same amount of time for a rorqual to open and to close its mouth (Fig. 2), a finding that does not falsify the 'springloaded' jaw hypothesis. Arnold et al. (2005) demonstrated that minke whales had maximum gape angles of only $40^{\circ}$, although these data were documented during non-feeding gulps that appeared to be behavioral displays. However, minke whales were also observed to depress the mandibles to approximately $70^{\circ}$ during 'inter-mandibular gulps' (Arnold et al. 2005), a jaw compliance that is comparable to what was observed here (Fig. 2) as well as in several previous studies (Lambertsen et al. 1995, Brodie 2001).

nitude of this cost may vary according to differences in morphology, behavior, and mechanical scaling effects.

\section{Engulfment volume}

Our mechanical model shows how a $20 \mathrm{~m}$ adult fin whale can engulf, on average, $71 \mathrm{~m}^{3}$ of water, a volume that is larger than that of the whale's entire body in its initial state. The reconfiguration of the buccal cavity that is predicted to accommodate this volume is well within the mechanical properties demonstrated by Orton \& Brodie (1987). The impressive engulfment capacity of rorquals is quite obvious from photographs of lunge feeding near the sea surface. The magnitude of the engulfed volume has been the subject of a great deal of speculation, with estimates based on anecdote (Pivorunas 1979), aerial photographs (Storro-Patterson 1981), and post mortem specimens (Lockyer 1981). These authors predicted a wide range of engulfment volumes, ranging from 10 to $600 \%$ of the whales' initial body volume. Based on our model, we suggest that the majority of fin whale lunges result in a volume of water that ranges from 120 to $160 \%$ body volume (Fig. 3).

Post mortem observations (Schulte 1916) and experiments (Lambertsen et al. 1995, Brodie 2001) suggest the temporomandibular joint and associated myotendinous structures act like a spring to store kinetic energy during mouth opening, which, in turn, could be used to help power mouth closure (Sanderson \&
If rorquals are able to control how far the mandibles are depressed during a lunge, then the magnitude of the engulfed volume may be under voluntary control (Arnold et al. 2005). Given the link between drag and engulfment volume (Figs. 4 to 6), rorquals should then be able to take smaller gulps at a relatively lower energetic cost. This modal feeding behavior may be advantageous when lunges are directed towards smaller aggregations of prey. To capture more agile prey, however, we predict that rorquals will increase maximum lunge speed rather than limit maximum gape angle. A higher attack speed coupled with an enlarged mouth will reduce the detrimental scaling effects of unsteady locomotion that cause large predators to be much less maneuverable than their smaller prey (Webb \& de Buffrenil 1990, Domenici 2001).

Unlike other large continuous ram filter-feeding vertebrates, such as the right whale Eubalaena spp. and basking shark Cetorhinus maximus, lunge feeding in rorquals is largely a matter of processing after seizing parts of large aggregations of krill and copepods or schools of fish. In this perspective, the raptorial feeding used by odontocetes to capture individual prey items may not be functionally different from the feeding strategy used by rorquals: lunge-feeding mysticetes are simply pursuing individual superorganisms. Therefore, large aggregations of prey represent a unit that may be less maneuverable than its individual members (Webb \& de Buffrenil 1990, Domenici 2001), thereby increasing the success rate of a predation event. 


\section{Filter performance}

From the time observed between lunges at depth (Goldbogen et al. 2006), the large engulfment volume calculated here is apparently filtered at a rapid rate (Table 2). However, this mass flow rate distributed over the large filter surface area yielded moderate $\mathrm{Re}$ for fluid flow past the baleen fringes. After passing through the fringes, water then passes through the gaps between baleen plates, for which we estimate high Re. Whether such flow is laminar or turbulent will ultimately depend on the material properties (i.e. smoothness, flexural stiffness) of the baleen.

Remarkably, both the flow speed and Re for water flow past the baleen fringes $\left(0.8 \mathrm{~m} \mathrm{~s}^{-1}, 570\right)$ are similar to the values reported for gill rakers of pump suspension-feeding fishes ( 0.4 to $0.7 \mathrm{~m} \mathrm{~s}^{-1}, 150$ to 600 ; Sanderson et al. 2001) that employ cross-flow filtration. This comparison presents the possibility that the baleen fringes may also operate as a cross-flow filter rather than a dead-end sieve. This hypothesis is indirectly supported by the observations of Kot (2005), who reported a rebounding wave within the buccal cavity that travels largely parallel with the filtering surface. This mechanism would enhance filter efficiency and help avoid some of the difficulties of removing prey from baleen, a problem discussed in detail by Werth (2001).

\section{Lunge feeding to meet an energetic demand}

Based on data for fasting fin whales, Brodie (1975) estimated a daily energetic demand of $996 \mathrm{~kg}$ of krill per day. This prediction is strongly supported by the mean of 5 other recent models of baleen whale bioenergetics (Croll et al. 2006), which give a daily prey biomass requirement of $901 \pm 258 \mathrm{~kg}$. For an average krill density measured at baleen whale foraging sites (Croll et al. 2005), our model predicts a fin whale can obtain approximately $11 \mathrm{~kg}$ of krill per lunge (Table 2). By combining these data, we suggest an adult fin whale can meet its daily energetic demand with 83 lunges distributed over 21 foraging dives. Interestingly, this effort can be met by a foraging time of about $3 \mathrm{~h}$. The foraging effort predicted here, however, is strongly dependent on the density and depth of prey. Large rorquals that apparently put on $4 \%$ of their body weight daily during a summer feeding season (Lockyer 1981) would be predicted to forage for approximately $6 \mathrm{~h}$ from the model presented here. It seems that lunge feeding is a key mechanism not just for maintaining a large body size, but also to develop substantial lipid stores that are needed for long-term migration and fasting. For these reasons, we predict a high foraging efficiency for rorqual lunges despite high drag.
Drag

Our dynamic evaluation of the drag coefficient $\left(C_{\mathrm{D}}\right)$ reveals a remarkable increase in its value over the course of a lunge, by at least an order of magnitude (Fig. 4). Its initial value is comparable to those of wellstreamlined bodies, but quickly becomes far greater than even the values reported for hollow-half hemispheres concave to steady flow (see Vogel 1994). This time course of $C_{\mathrm{D}}$ is similar to values determined for an inflating circular parachute, which increases from 0.09 to 4.12 (Dneprov 1993, Peterson et al. 1996). The $C_{\mathrm{D}}$ values calculated here for a decelerating fin whale are also consistent with those determined for circular discs $\left(C_{\mathrm{D}}>5\right)$ when exposed to unsteady flows (Higuchi et al. 1996). Thus, it appears that lunge-feeding fin whales undergo a rapid transformation from a wellstreamlined shape to one that is extremely disposed to drag. This shape change is advantageous because drag arising from dynamic pressure is absolutely required to expand the buccal cavity (Orton \& Brodie 1987). The analogy between inflating parachutes and lunge-feeding whales is appropriate since the purpose in each scenario is to produce drag.

As the buccal cavity fills, separation of flow may occur along the lateral margins of the mandibles, but probably more so along the rostrum and exposed baleen. Early separation of flow will create large pressure differences along the body and increase drag on the body rather than the exposed buccal cavity. Thus, we predict that the rorqual mandible and surrounding tissues are well streamlined so that during a lunge, the mandibles themselves do not experience significant drag. Instead, dynamic pressure is increased within the area encompassed by the mandibles, thereby enhancing expansion of the buccal cavity. Preliminary measurements support a hydrodynamic design of the rorqual mandible (see also cross-sections by Pivorunas 1977, Lambertsen 1983), and this is now the focus of a current study already underway (Goldbogen \& Pyenson unpubl. data).

\section{Ecology and evolution}

Despite the high energetic cost of lunge feeding in fin whales, this specialized vertebrate feeding strategy has limited neither the ecological nor the evolutionary diversification of lunge-feeding baleen whales (Fig. 7). Thus, the selective advantages of lunge feeding, namely a large engulfment capacity that may render lunge feeding to be quite efficient overall, seem to outweigh the energetic cost of high drag. All members of the Balaenopteridae are lunge feeders, and, in terms of ecological specialization, extant bal- 


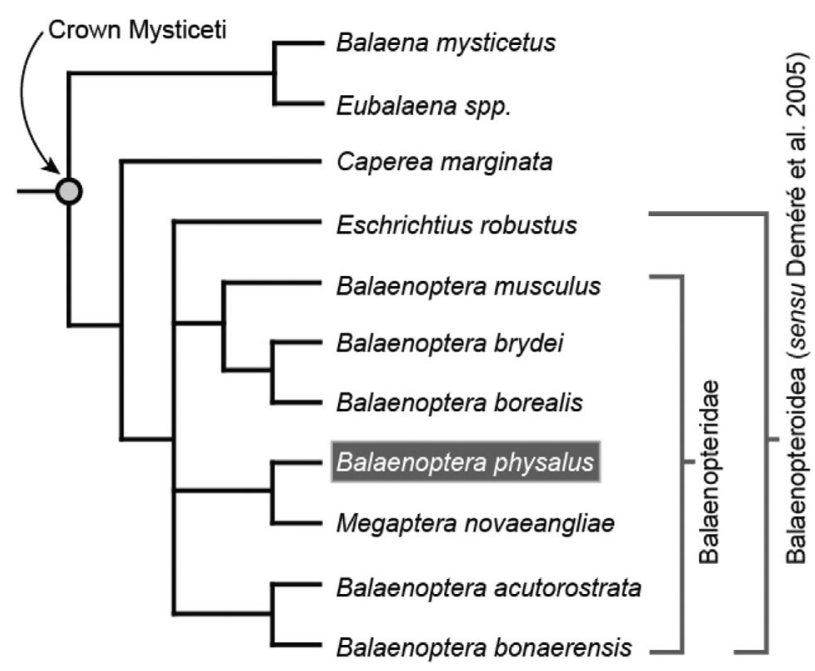

Fig. 7. A cladogram showing the relationships among living baleen whales lineages, using the topology presented by Sasaki et al. (2005). Balaenoptera physalus, or the fin whale, is the focus of this study, and it is highlighted by a gray box. Note the poor resolution (polytomy) within Balaenopteroidea (sensu Deméré et al. 2005) and the potential non-monophyly of Balaenopteridae and Balaenoptera. B. brydei is also likely polytypic (Sasaki et al. 2006)

aenopterid species range in discrete size categories from $7 \mathrm{~m}$ minke whales to $30 \mathrm{~m}$ blue whales, with concomitant prey and behavioral specializations that further partition modern balaenopterid feeding ecology (Mitchell 1974, Lockyer 1981, Tershy 1992). Furthermore, rorquals were major consumers of worldwide oceanic productivity before the advent of mechanized whaling, and, as such, they played a fundamental role in structuring ocean ecosystems (Croll et al. 2006).

Lunge feeding in balaenopterids contrasts significantly with the continuous ram feeding (Sanderson \& Wassersug 1993, Werth 2000) exhibited by right and bowhead whales (Balaenidae), which are the sister group to Balaenopteroidea (Balaenopteridae + gray whales; sensu Deméré et al. 2005). Rorquals are among the most speciose groups of living cetaceans, whereas balaenids comprise only a few species; a difference that is also observed in the generic diversity of these 2 groups throughout their evolutionary history (Lindberg \& Pyenson 2006). Preliminary reconstructions of body size in extinct balaenopteroids indicate that, ancestrally, this group of baleen whales did not exhibit the larger size categories of their extant relatives (Pyenson \& Sponberg 2007), and the same situation appears to be true for the balaenid lineage as well (Bisconti 2005). These data, together with the apparent monophyly of Balaeopteroidea (Deméré et al. 2005), provide tentative support for an evolutionary scenario advanced by Lambertsen et al. (1995), which frames lunge feeding as a putative key innovation that enhanced a pre-existing suite of engulfment-assisting morphological characters (Kimura 2002, Deméré et al. 2005). Moreover, the present diversity of living balaenopterids (in terms of both prey preferences and body size range; Lindberg \& Pyenson 2006), sister group comparisons, and ancestral body size reconstruction all suggest that the advent of lunge feeding provided an ecological advantage that promoted large body size in the balaenopterid lineage, eventually providing the opportunity for the evolution of some of the largest organisms that have ever existed. However, these hypotheses cannot be tested until (1) further comparative work identifies clear evolutionary transformations in the cranial and mandibular character complexes (e.g. temporomandibular joint), (2) phylogenetic analysis resolves the placement of key fossil taxa (Deméré et al. 2005), and (3) the pattern of body size evolution in mysticetes becomes clearly elucidated.

Acknowledgements. Funding for tag operations was provided by the US Navy. We thank B. Burgess for the development of the Bioacoustic Probe. We also thank the Cascadia Research Collective, E. Oleson, and M. McDonald for their role in tagging fin whales. We thank 3 anonymous reviewers for their thorough comments that enhanced the content and quality of this paper. Funding for the development of this physical model and manuscript was provided by NSERC to R.E.S. Support for this work was also provided by a travel grant from UCMP Remington Kellogg Fund and NSF GRF to N.D.P. We especially thank J. Potvin for critical feedback and advice regarding the unsteady evaluation of drag. Members of the C4NT in San Diego, including R. Burgundy, B. Fantana and $\mathrm{B}$. Tamland, provided valuable motivation during the course of this study. We thank C. Conroy, S. Davenport, K. Fahy, D. Janiger and C. Potter for access to specimens. We also thank B. Ahlborn, L. Barnes, P. Brodie, J. Calambokidis, F. Fish, J. Gosline, J. Hildebrand, D. Janiger, D. Lindberg, E. Mitchell, J. Meir, G. Szulgit, S. Vogel, and M. Wedel for their comments, assistance and encouragement. This paper is UCMP Contribution No. 1941.

\section{LITERATURE CITED}

Acevedo-Gutierrez A, Croll DA, Tershy BR (2002) High feeding costs limit dive time in the largest whales. J Exp Biol 205:1747-1753

Ahlborn BK (2004) Zoological physics, 2nd edn. Springer-Verlag, Berlin

Arnold PW, Birtles RA, Sobtzick S, Matthews M, Dunstan A (2005) Gulping behaviour in rorqual whales: underwater observations and functional interpretation. Mem Queensl Mus 51:309-332

Bisconti M (2005) Skull morphology and phylogenetic relationships of a new dimunitive balaenid from the Lower Pliocene of Belgium. Palaeontology 48:793-816. doi: 10.1111/j.1475-4983.2005.00488.x

Blix AS, Folkow LP (1995) Daily energy expenditure in free living minke whales. Acta Physiol Scand 153:61-66 
Bose N, Lien J (1989) Propulsion of a fin whale (Balaenoptera physalus): why the fin whale is a fast swimmer. Proc R Soc Lond B 237:175-200

Brodie PF (1975) Cetacean energetics, an overview of intraspecific size variation. Ecology 56:152-161

Brodie PF (1993) Noise generated by the jaw actions of feeding fin whales. Can J Zool 71:2546-2550

Brodie PF (2001) Feeding mechanics of rorquals (Balaenoptera sp.). In: Mazin JM, de Buffrenil V (eds) Secondary adaptation of tetrapods to life in water. Verlag Dr. Friedrich Pfeil, München, p 345-352

Butler PJ, Jones DR (1982) The comparative physiology of diving in vertebrates. Adv Comp Physiol Biochem 8: 179-364

Croll DA, Acevedo-Gutierrez A, Tershy BR, Urban-Ramirez J (2001) The diving behavior of blue and fin whales: Is dive duration shorter than expected based on oxygen stores? Comp Biochem Physiol A 129:797-809

Croll DA, Marinovic B, Benson S, Chavez FP, Black N, Ternullo R, Tershy BR (2005) From wind to whales: trophic links in a coastal upwelling system. Mar Ecol Prog Ser 289:117-130

Croll DA, Kudela R, Tershy BR (2006) Ecosystem impact of the decline of large whales in the North Pacific. In: Estes JA, et al (eds) Whales, whaling and ocean ecosystems. University of California Press, Berkeley, p 202-214

Deméré TA, Berta A, McGowen MR (2005) The taxonomic and evolutionary history of fossil and modern balaenopteroid mysticetes. J Mamm Evol 12:99-143. doi: 10.1007/s10914-005-6944-3

Dneprov IV (1993) Computation of aeroelastic characteristics and stress-strained state of parachutes. In: Proceedings of the 12th RAeS/AIAA Aerodyn Decelerator Systems Technol Conf and Seminar. AIAA, London, p 93-1237

Domenici P (2001) Scaling the locomotor performance in predator-prey interactions: from fish to killer whales. Comp Biochem Physiol A 131:169-182

Folkens P (2003) National Audubon Society guide to marine mammals of the world. Chanticleer Press, New York, p 230-231

Goldbogen JA, Calambokidis J, Shadwick RE, Oleson EM, McDonald MA, Hildebrand JA (2006) Kinematics of foraging dives and lunge-feeding in fin whales. J Exp Biol 209: 1231-1244

Halsey LG, Butler PJ, Blackburn TM (2006) A phylogenetic analysis of the allometry of diving. Am Nat 167:276-287

Higuchi H, Balligand H, Strickland JH (1996) Numerical and experimental investigations of the flow over a disk undergoing unsteady motion. J Fluids Struct 10:705-719

Iversen HW, Balent R (1951) A correlating modulus for fluid resistance in accelerated motions. J Appl Phys 22:324-328

Kawamura A (1980) A review of food of balaenopterid whales. Sci Rep Whales Res Inst 32:155-197

Kimura T (2002) Feeding strategy of an Early Miocene cetothere from the Toyama and Akeyo Formations, central Japan. Paleontol Res 6:2

Kot BW (2005) Rorqual whale surface-feeding strategies: biomechanical aspects of feeding anatomy and exploitation of prey aggregations along tidal fronts. MSc thesis, University of California, Los Angeles

Krutzikowsky GK, Mate BR (2000) Dive and surface characteristics of bowhead whales (Balaena mysticetus) in the Beaufort and Chukchi Seas. Can J Zool 78:1182-1198

Lambertsen RH (1983) Internal mechanism of rorqual feeding. J Mammal 64:76-88

Lambertsen R, Ulrich N, Straley J (1995) Frontomandibular stay of balaenopteridae-a mechanism for momentum recapture during feeding. J Mamm 76:877-899
Lindberg DR, Pyenson ND (2006) Evolutionary patterns in Cetacea: fishing up prey size through deep time. In: Estes JA DeMaster DP, Doak DF, Williams TM, Brownell RL Jr (eds) Whales, whaling and ocean ecosystems. University of California Press, Berkeley, p 67-81

Lockyer C (1976) Body weights of some species of large whales. J Cons Int Explor Mer 36:259-273

Lockyer C (1981) Growth and energy budgets of large baleen whales from the southern hemisphere. In: Mammals in the seas, Vol. III. General papers and large Cetaceans. FAO Fish Ser 5:379-487

Lockyer C, Waters T (1986) Weights and anatomical measurements of Northeastern Atlantic fin (Balaneoptera physalus, Linnaeus) and sei (B. borealis, Lesson) whales. Mar Mamm Sci 2:169-185

Mitchell ED (1974) Trophic relationships and competition for food in Northwest Atlantic whales. In: Proceedings of the Canadian Socitey of Zoology Annual Meeting. Canadian Society of Zoology, Fredericton, p 123-133

Nerini M (1984) A review of gray whale feeding ecology. In: Jones ML, Swartz SL, Leatherwood S (eds) The gray whale, Eschrichtius robustus. Academic Press, New York, p 423-450

Orton LS, Brodie PF (1987) Engulfing mechanics of fin whales. Can J Zool 65:2898-2907

Panigada S, Zanardelli M, Canese S, Jahoda M (1999) How deep can baleen whales dive? Mar Ecol Prog Ser 187: 309-311

Peterson CW, Strickland JH, Higuchi H (1996) The fluid dynamics of parachute inflation. Annu Rev Fluid Mech 28: 361-387

Pivorunas A (1976) A mathematical consideration of the function of baleen plates and their fringes. Sci Rep Whales Res Inst 28:37-55

Pivorunas A (1977) Fibrocartilage skeleton and related structures of ventral pouch of balaenopterid whales. J Morphol 151:299-313

Pivorunas A (1979) The feeding mechanisms of baleen whales. Am Sci 67:432-440

Potvin J, Peek G, Brocato B (2003) New model of decelerating bluff body drag. J Aircraft 40:370-377

Pyenson ND, Sponberg S (2007) Reconstructing body size in extinct crown Cetacea using allometric scaling, phylogenetic comparative methods, and tests from the fossil record. In: Warren A (ed) Conf on Australiasian Vertebrate Evolution, Palaeontology and Systematics 2007. Geol Soc Aust Abst 85:51-52

Sanderson SL, Wassersug R (1993) Convergent and alternative designs for vertebrate suspension feeding. In: Hanken J, Hall BK (eds) The skull: functional and evolutionary mechanisms. University of Chicago Press, p 37-112

Sanderson SL, Cheer AY, Goodrich JS, Graziano JD, Callan WT (2001) Crossflow filtration in suspension-feeding fishes. Nature 412:439-441

Sasaki T, Nikaido M, Hamilton H, Goto M and 6 others (2005) Mitochondrial phylogenetics and evolution of mysticete whales. Syst Biol 54:77-90

Sasaki T, Nikaido M, Wada S, Yamada TK, Cao Y, Hasegawa M, Okada N (2006) Balaenoptera omurai is a newly discovered baleen whale that represents an ancient evolutionary lineage. Mol Phylogenet Evol 41:40-52

Schulte HVW (1916) Anatomy of a foetus. Balaenoptera borealis. Mem Am Mus Nat Hist 6:389-502

Stockin KA, Fairbairns RS, Parsons ECM, Sims DW (2001) Effects of diel and seasonal cycles on the dive duration of the minke whale (Balaenoptera acutorostrata). J Mar Biol Assoc UK 81:189-190 
Storro-Patterson R (1981) The great gulping blue whales. Oceans 14:16-17

Tershy B (1992) Body size, diet, habitat use, and social behavior of Balaenoptera whales in the Gulf of California. J Mamm 73:477-486

True FW (1904) Whalebone whales of the western North Atlantic. Smithson Contrib Knowledge 33:1-332

Vogel S (1994) Life in moving fluids: the physical biology of flow, 2nd edn. Princeton University Press, Princeton, NJ

Webb PW, de Buffrenil V (1990) Locomotion in the biology

Editorial responsibility: Rory Wilson (Contributing Editor), Swansea, UK of large aquatic vertebrates. Trans Am Fish Soc 119: 629-641

Werth AJ (2000) Feeding in marine mammals. In: Schwenk K (ed) Feeding: form, function and evolution in tetrapod vertebrates. Academic Press, New York, p 475-514

Werth AJ (2001) How do mysticetes remove prey trapped in baleen? Bull Mus Comp Zool 156:189-203

Williams TM (1999) The evolution of cost efficient swimming in marine mammals: limits to energetic optimization. Philos Trans R Soc Lond B 354:193-201

Submitted: March 27, 2007; Accepted: May 21, 2007

Proofs received from author(s): October 16, 2007 